\title{
Endurance training improves insulin sensitivity and body composition in prostate cancer patients treated with androgen deprivation therapy
}

Thine Hvid', Kamilla Winding', Anders Rinnov', Thomas Dejgaard', Carsten Thomsen², Peter Iversen $^{3}$, Klaus Brasso ${ }^{3}$, Kari J Mikines ${ }^{4}$, Gerrit van Hall, ${ }^{1,5}$, Birgitte Lindegaard', Thomas P J Solomon' and Bente K Pedersen ${ }^{1}$

${ }^{1}$ The Centre of Inflammation and Metabolism, Department of Infectious Diseases and Copenhagen Muscle Research Centre, Rigshospitalet, Faculty of Health Sciences, University of Copenhagen, Copenhagen, Denmark

${ }^{2}$ Department of Diagnostic Radiology, Rigshospitalet, Copenhagen, Denmark

${ }^{3}$ Department of Urology, Rigshospitalet, Copenhagen, Denmark

${ }^{4}$ Department of Urology, Herlev University Hospital, Copenhagen, Denmark

${ }^{5}$ The Metabolic Mass Spectrometry Facility, Rigshospitalet, Copenhagen, Denmark

Correspondence should be addressed to T Hvid

Email

thvid@inflammationmetabolism.dk

\begin{abstract}
Insulin resistance and changes in body composition are side effects of androgen deprivation therapy (ADT) given to prostate cancer patients. The present study investigated whether endurance training improves insulin sensitivity and body composition in ADT-treated prostate cancer patients. Nine men undergoing ADT for prostate cancer and ten healthy men with normal testosterone levels underwent 12 weeks of endurance training. Primary endpoints were insulin sensitivity (euglycemic-hyperinsulinemic clamps with concomitant glucose-tracer infusion) and body composition (dual-energy $\mathrm{X}$-ray absorptiometry and magnetic resonance imaging). The secondary endpoint was systemic inflammation. Statistical analysis was carried out using two-way ANOVA. Endurance training increased $\mathrm{VO}_{2 \max }\left(\mathrm{ml}\left(\mathrm{O}_{2}\right) / \mathrm{min}\right.$ per $\left.\mathrm{kg}\right)$ by 11 and $13 \%$ in the patients and controls respectively $(P<0.0001)$. The patients and controls demonstrated an increase in peripheral tissue insulin sensitivity of 14 and $11 \%$ respectively $(P<0.05)$, with no effect on hepatic insulin sensitivity $(P=0.32)$. Muscle protein content of GLUT4 (SLC2A4) and total AKT (AKT1) was also increased in response to the training $(P<0.05$ and $P<0.01$ respectively). Body weight $(P<0.0001)$ and whole-body fat mass $(\mathrm{FM})(P<0.01)$ were reduced, while lean body mass $(P=0.99)$ was unchanged. Additionally, reductions were observed in abdominal $(P<0.01)$, subcutaneous $(P<0.05)$, and visceral $(P<0.01) \mathrm{FM}$ amounts. The concentrations of plasma markers of systemic inflammation were unchanged in response to the training. No group $\times$ time interactions were observed, except for thigh intermuscular adipose tissue (IMAT) $(P=0.01)$, reflecting a significant reduction in the amount of IMAT in the controls $(P<0.05)$ not observed in the patients $(P=0.64)$. In response to endurance training, ADT-treated prostate cancer patients exhibited improved insulin sensitivity and body composition to a similar degree as eugonadal men.
\end{abstract}

Key Words

- prostate cancer

- androgen deprivation therapy

- endurance training

- insulin sensitivity and body composition http://erc.endocrinology-journals.org DOI: 10.1530/ERC-12-0393
(C) 2013 Society for Endocrinology Printed in Great Britain
Published by Bioscientifica Ltd
Endocrine-Related Cancer

(2013) 20, 621-632 


\section{Introduction}

The cornerstone treatment for men with advanced and metastatic prostate cancer is androgen deprivation therapy (ADT). ADT results in castration levels of serum testosterone that cause delayed tumor progression and, in certain stages of the disease, also improved cancer-specific survival (Sharifi et al. 2005). However, ADT also causes metabolic complications such as hyperlipidemia (Smith et al. 2002) and insulin resistance (Basaria et al. 2006, Smith et al. 2006, 2008a, Hamilton et al. 2011) and unfavorable changes in body composition such as a loss of lean body mass (LBM; Berruti et al. 2002, Smith 2004, Lee et al. 2005, Smith et al. 2008a, b, Hamilton et al. 2011) and a gain in fat mass (FM; Berruti et al. 2002, Smith 2004, Boxer et al. 2005, Greenspan et al. 2005, Lee et al. 2005, Smith et al. 2008a,b). Increased FM following ADT is particularly pronounced in the abdominal compartment (Braga-Basaria et al. 2006) and may reflect an accumulation of both visceral adipose tissue (VAT) and subcutaneous adipose tissue (SAT) (Smith et al. 2002, 2008b, Hamilton et al. 2011).

Obesity is associated with a state of low-grade inflammation (Cancello \& Clement 2006). The consequence of the ADT-induced increase in total and abdominal FM in prostate cancer patients is, however, controversial regarding inflammation status. Increased systemic concentrations of inflammatory cytokines in ADT-treated prostate cancer patients have been documented, but they may be dependent on ADT duration (Maggio et al. 2006, Smith et al. 2008a,b, Saylor et al. 2012) and whether or not the cancer is castration resistant (Drachenberg et al. 1999, Wise et al. 2000).

Insulin resistance and abdominal obesity characterize the metabolic syndrome and are risk factors for type 2 diabetes (Lechleitner 2008). Prostate cancer patients managed with ADT have an increased risk of the metabolic syndrome and diabetes compared with patients not receiving ADT and healthy controls (Braga-Basaria et al. 2006, Keating et al. 2006, Kintzel et al. 2008). A growing number of studies have also reported of an increased risk of cardiovascular disease in ADT-treated prostate cancer patients (Faris \& Smith 2010). Strategies that prevent the adverse effects of ADT on insulin resistance and body composition seem crucial to decrease the incidence of these obesity-related diseases. Several studies have investigated the effect of strength training alone (Segal et al. 2003, Galvao et al. 2006, Hansen et al. 2009, Alberga et al. 2012, Hanson et al. 2013) or in combination with light aerobic training (Galvao et al. 2010, 2011, Bourke et al. 2011). Strength training can prevent the deterioration in
LBM and reduce increases in FM in ADT-treated men with prostate cancer (Alberga et al. 2012). In contrast, neither the loss of LBM nor the increase in FM is prevented by endurance training (Alberga et al. 2012), suggesting that the lack of testosterone may hinder the beneficial effects of endurance training on body composition. Nevertheless, it remains to be determined whether endurance training alters the regional distribution of adiposity. Visceral adiposity per se may be an independent risk factor for the development of insulin resistance, type 2 diabetes, and features of the metabolic syndrome (Fox et al. 2007).

Exercise training improves insulin sensitivity (Hawley $\&$ Lessard 2008). This effect of training has never been investigated in prostate cancer patients receiving ADT. Exercise also induces anti-inflammatory effects (Mathur \& Pedersen 2008). While strength training alone does not improve the inflammation status in ADT-treated prostate cancer patients (Galvao et al. 2008), combined aerobic and strength training results in decreased systemic inflammation (Galvao et al. 2010), suggestive of an anti-inflammatory effect of endurance training alone in such patients.

The primary aim of this study was to investigate the effect of 12 weeks of supervised endurance training on insulin sensitivity and body composition in ADT-treated prostate cancer patients, with special reference to visceral fat. The secondary aim was to investigate the effect of endurance training on the concentrations of systemic markers of inflammation in this group of patients. To elucidate whether men with testosterone ablation have the same beneficial effects of endurance training as men with normal levels of testosterone, a group of age-matched healthy eugonadal men were also included in the study.

\section{Subjects and methods}

\section{Subjects}

Prostate cancer patients $(n=10)$ receiving LHRH agonist therapy (ADT) for $>3$ months were enrolled from the Department of Urology, Rigshospitalet, and Department of Urology, Herlev Hospital, to undergo a 3-month exercise training intervention. The patients were receiving LHRH agonist as either $10.8 \mathrm{mg}$ injections of Zoladex (AstraZeneca) every third month or as $50 \mathrm{mg}$ Vastas implants annually (Orion Pharma, Nivå, Denmark). All patients had castration levels of testosterone $(<1.7 \mathrm{nmol} / \mathrm{l})$. Control subjects $(n=11)$ were healthy males matched by age, BMI, and aerobic fitness with

Published by Bioscientifica Ltd. 
normal testosterone levels $(10.0-28.0 \mathrm{nmol} / \mathrm{l})$. Before inclusion, a medical examination with blood test screening was performed. The purpose of the study, possible risks, and discomforts were explained to the subjects and written consent was obtained. The study was approved by the Ethical Committee of Copenhagen and Frederiksberg (H-4-2009-102) and was performed in accordance with the Declaration of Helsinki. Exclusion criteria included severe cardiovascular disease, severe arthritis, severe neuropathy, severe hypertension, therapy with antidiabetic agents, and exercise training $>2$ times per week. Due to poor adherence to the training, one subject in each group was excluded from the study. The final study population comprised nine prostate cancer patients and ten control subjects.

\section{Training protocol}

The subjects underwent supervised endurance training on a cycle ergometer three times per week for 12 weeks. Heart rate was continuously monitored (RS400; Polar, Kempele, Finland). The participants trained at the heart rate corresponding to the desired percentage of maximal oxygen consumption $\left(\mathrm{VO}_{2 \max }\right)$ measured during an incremental workload exercise test (described below). Each training session consisted of 5 min of warm up, $35 \mathrm{~min}$ of interval training, and $5 \mathrm{~min}$ of cool down. Varying interval programs were used with the intention to keep up motivation and adherence to the training. The training consisted of $5-10$-min intervals $(55-75 \%$ of $\mathrm{VO}_{2 \max }$ ) on the first week day of the training, 5-25-min intervals $\left(55-75 \%\right.$ of $\left.\mathrm{VO}_{2 \max }\right)$ on the second day, and 1-5-min intervals $\left(50-100 \%\right.$ of $\mathrm{VO}_{2 \max }$ ) on the third day. The mean training intensity was targeted at $65 \%$ of $\mathrm{VO}_{2 \max }$ in the first 6 weeks and at $75 \%$ of $\mathrm{VO}_{2 \max }$ in the last 6 weeks. The subjects were allowed to miss no more than $10 \%$ of the training sessions.

\section{Diet and physical activity}

The subjects were instructed to maintain their habitual diet and level of physical activity during the study. The subjects completed the diet and activity records for 3 days in the beginning of the training period and for 3 days at the end of the training period. Energy intake and expenditure were determined using the Dankost Sport software (Dansk Catering Center A/S, Copenhagen, Denmark). Complete registration was, however, only provided for 11 subjects. Diet was also registered 2 days before the pre-intervention clamp, and the subjects were instructed to ingest the same diet 2 days before the postintervention clamp. The subjects were requested not to perform any strenuous physical activity 2 days before the clamp measurements and oral glucose tolerance test (OGTT).

\section{Maximal oxygen consumption $\left(\mathrm{VO}_{2 \max }\right)$ test}

Prior to the study, the subjects underwent an incremental exercise test to volitional fatigue on a cadence independent cycle ergometer. Oxygen consumption $\left(\mathrm{VO}_{2}\right)$ was measured by indirect calorimetry (Quark b2; CosMed, Rome, Italy). $\mathrm{VO}_{2 \max }$ was considered obtained when two of the following three criteria were achieved: i) respiratory exchange ratio $\geq 1.10$; ii) $\mathrm{VO}_{2}$ reached a plateau; and iii) cycling cadence $<60$ r.p.m. for more than 10 s. Heart rate was recorded continuously during the test. The $\mathrm{VO}_{2 \max }$ test was repeated after 6 weeks of training to adjust the absolute workload and following the 12 weeks of training.

\section{Oral glucose tolerance test}

A standard 2-h OGTT with a glucose load of $75 \mathrm{~g}$ was performed following an overnight fast and pre and post training. The post-exercise OGTT was performed $48-96 \mathrm{~h}$ after the last exercise bout. Blood samples were collected into glass tubes containing EDTA at $-10,-5,0,30,60$, 90 , and $120 \mathrm{~min}$ and were immediately spun at $3500 \boldsymbol{g}$ for $15 \mathrm{~min}$ at $4{ }^{\circ} \mathrm{C}$. Plasma was isolated and stored at $-20^{\circ} \mathrm{C}$ until analyzed. The area under the curve (AUC) for insulin and glucose was calculated using the trapezoidal rule.

\section{Euglycemic-hyperinsulinemic clamp}

A euglycemic-hyperinsulinemic clamp was performed before and after the training period. The subjects reported to the laboratory between 0700 and $0800 \mathrm{~h}$ after an overnight fast $(12 \mathrm{~h})$ and $46-48 \mathrm{~h}$ after the $\mathrm{VO}_{2 \max }$ test both pre and post training. An i.v. catheter was inserted into the antecubital vein of one arm for the infusion of insulin and glucose. For blood sampling, a second catheter was placed into a dorsal hand vein on the contralateral arm. The hand was wrapped in a heating blanket to arterialize venous blood samples. After obtaining baseline blood samples, an i.v. priming dose of $17.6 \mu \mathrm{mol} / \mathrm{kg}$ $\left[6,6-{ }^{2} \mathrm{H}_{2}\right]$ glucose was injected. Later, a $0.4 \mu \mathrm{mol} / \mathrm{min}$ per $\mathrm{kg}$ infusion of $\left[6,6-{ }^{2} \mathrm{H}_{2}\right]$ glucose was injected. After $2 \mathrm{~h}$ of $\left[6,6-{ }^{2} \mathrm{H}_{2}\right]$ glucose infusion, a $3-\mathrm{h} 40 \mathrm{mU} / \mathrm{m}^{2}$ per $\mathrm{min}$ infusion of insulin (Actrapid; Novo Nordisk, Bagsværd, Denmark) was injected. After 30 min of insulin infusion, the infusion rate of $\left[6,6-{ }^{2} \mathrm{H}_{2}\right]$ glucose was increased to

Published by Bioscientifica Ltd. 
$1.2 \mu \mathrm{mol} / \mathrm{min}$ per $\mathrm{kg}$. Arterialized plasma glucose concentration was measured every $10 \mathrm{~min}$ (EML 105, Radiometer, Brønshøj, Denmark) throughout the clamp, and euglycemia $(5.5 \mathrm{mmol} / \mathrm{l})$ was achieved by a variablerate infusion of $20 \%(\mathrm{w} / \mathrm{v})$ glucose. Blood samples for the determination of tracer-to-tracee ratio were collected every $10 \mathrm{~min}$ during the last $30 \mathrm{~min}$ of both the basal and insulin-stimulated states.

\section{Tissue samples}

Muscle tissue from $\mathrm{m}$. vastus lateralis was obtained under local anesthesia using the percutaneous needle biopsy method with suction during the basal state on the clamp days. Tissue samples were cleaned free of blood and connective tissue and quickly frozen in liquid nitrogen and stored at $-80{ }^{\circ} \mathrm{C}$ until analyzed.

\section{Body composition}

Whole-body fat-free mass, FM, and trunk FM were measured before and after the intervention using dualenergy X-ray absorptiometry (Lunar Prodigy, version 8.8; GE Medical Systems, Madison, WI, USA).

Magnetic resonance (MR) imaging was performed using a 3-Tesla MR scanner (Siemens Magnetom Total imaging matrix magnetic resonance scanner, Erlangen, Germany). Multi-slice images from the top of the femoral head to the upper border of the liver were analyzed using the software program Mango (Multi-Images Analysis GUI). VAT volume was calculated according to the slice thickness and cross-sectional area of each image. SAT volume was calculated by subtracting VAT volume from the total abdominal fat volume. VAT was defined as the amount of fat deposited around the internal organs delineated by the inner wall of the abdominal muscle. SAT was defined as adipose tissue located directly beneath the skin. The right thigh was measured from the femoral head to the tibiofemoral joint line, and the average volume of intermuscular adipose tissue (IMAT) was measured in the middle one-third of the thigh. IMAT was defined as adipose tissue located beneath the fascia and between muscles. All MR analyses were performed by the same investigator in a blinded manner.

\section{Laboratory analysis}

Plasma plasminogen activator inhibitor-1 (PAI-1) concentration was measured using ELISA (R\&D Systems, Minneapolis, MN, USA), and interleukin 6 (IL6), tumor necrosis factor $\alpha$ (TNF $\alpha(\mathrm{TNF}))$, adiponectin, and leptin concentrations were measured using ELISA (Meso Scale Discovery, Gaithersburg, MD, USA). All samples were run as duplicates and mean concentrations were calculated. Total cholesterol, HDL-cholesterol, LDL-cholesterol, triglycerides, testosterone, prostate-specific antigen (PSA), glucose, and insulin concentrations were measured using local routine laboratory methods.

Muscle biopsies were prepared for homogenization using a lysis buffer (50 mM Tris- $\mathrm{HCl}, 150 \mathrm{mM} \mathrm{NaCl}, 1 \mathrm{mM}$ EDTA, $1 \mathrm{mM}$ EGTA, $50 \mathrm{mM}$ sodium fluoride, and $5 \mathrm{mM}$ sodium pyrophosphate) and homogenized using TissueLyser (Qiagen). The concentrations of the muscle lysates were measured using the Bradford assay (Bio-Rad Protein Assay, \#500-0006), and muscle lysates were separated on TGX 4-14\% gel (Bio-Rad) and transferred onto PVDF membranes (Life Technologies) before incubation with the appropriate antibodies. The primary antibodies used were total AKT (no. 9272, Cell Signalling Technology, Danvers, MA, USA) and glucose transporter 4 (GLUT4) (Thermo Scientific, Slangerup, Denmark). The secondary antibodies used were anti-rabbit HRP (no. 7074, Cell Signalling Technology) for AKT (AKT1) and anti-rabbit HRP (P0448, Dako, Glostrup, Denmark) for GLUT4 (SLC2A4). The intensities of the protein bands were detected using Image Lab 3.0 (Bio-Rad) and normalized to the intensity of the Reactive Brown (RB) total protein stain. Results are reported in arbitrary units.

\section{Glucose kinetics calculations}

Enrichment of plasma glucose was determined as described previously (Plomgaard et al. 2005) using liquid chromatography-mass spectrometry (Finnegan aQa). The rate of appearance $\left(R_{a}\right)$ and rate of disappearance $\left(R_{d}\right)$ of glucose were determined in the basal state and during the last 30 min of the clamp, where a steady state of glucose infusion and glucose concentration was achieved, using the steady-state single pool model of Steele (Steele 1959). Hepatic insulin sensitivity was estimated as the difference between total $\mathrm{R}_{\mathrm{a}}$ and exogenous glucose infusion rate during the steady-state hyperinsulinemia. Peripheral tissue insulin sensitivity was estimated as $R_{d}$ during the steady-state hyperinsulinemia.

\section{Statistical analysis}

Data were analyzed using SAS 9.1.3 (SAS Institute, Inc., Cary, NC, USA). All outcome variables were checked for normal distribution and were log-transformed to achieve

Published by Bioscientifica Ltd. 
an approximate normal distribution when necessary. Baseline differences between the groups were assessed using unpaired $t$-tests. To investigate whether ADT-treated prostate cancer patients are able to achieve the same beneficial effects of endurance training as an eugonadal control group of healthy men, a two-way ANOVA (group $\times$ time) with repeated measures was performed. A significant interaction indicates that the outcome variable is influenced differently by the training regimen in the two groups. Thus, only if a significant interaction was observed, a paired $t$-test for independent groups was performed to identify within-group differences from pre to post training. A significant effect of time reflects a significant effect of the training regimen in the two groups pooled together. Results are presented as means \pm s.D., if not otherwise stated. $P<0.05$ was considered to be significant.

\section{Results}

\section{Baseline characteristics}

The baseline characteristics of the patient and control groups are given in Table 1 . The patients had castration levels of testosterone $(0.5 \pm 0.4 \mathrm{nmol} / 1)$ that were

Table 1 Baseline comparisons between the patients and controls

\begin{tabular}{|c|c|c|c|}
\hline & Patients $(n=9)$ & Controls $(n=10)$ & $P$ value \\
\hline Age (years) & $67.8 \pm 6.4$ & $68.5 \pm 3.5$ & 0.76 \\
\hline Testosterone $(\mathrm{nmol} / \mathrm{l})$ & $0.5 \pm 0.4$ & $13.1 \pm 2.4$ & $<0.001$ \\
\hline Type 2 diabetes $(n)$ & $2(9)$ & $0(10)$ & NA \\
\hline Impaired glucose tolerance $(n)$ & $1(9)$ & $1(10)$ & NA \\
\hline \multicolumn{4}{|l|}{ Cancer characteristics } \\
\hline \multicolumn{4}{|l|}{ Stage $(n)$} \\
\hline $\mathrm{T} 1 \mathrm{a} / \mathrm{b}$ & 1 & NA & NA \\
\hline $\mathrm{T} 2 \mathrm{a} / \mathrm{b}$ & 4 & NA & NA \\
\hline $\mathrm{T} 3 \mathrm{a} / \mathrm{b}$ & 4 & NA & NA \\
\hline \multicolumn{4}{|l|}{ Gleason score $(n)$} \\
\hline 7 & 1 & NA & NA \\
\hline 8 & 5 & NA & NA \\
\hline 9 & 3 & NA & NA \\
\hline ADT duration (month) ${ }^{a}$ & $9(4-71)$ & NA & NA \\
\hline Short-term/long-term ADT $(n)$ & $1 / 8$ & NA & NA \\
\hline PSA $(\mu \mathrm{g} / \mathrm{l})^{\mathrm{a}}$ & $0.90(0.10-6.70)$ & NA & NA \\
\hline \multicolumn{4}{|l|}{ Fitness } \\
\hline $\mathrm{VO}_{2 \max }\left(\mathrm{ml}\left(\mathrm{O}_{2}\right) / \min\right.$ per kg) & $25.2 \pm 4.2$ & $27.1 \pm 3.3$ & 0.29 \\
\hline $\mathrm{VO}_{2 \max }\left(\mathrm{ml}\left(\mathrm{O}_{2}\right) / \mathrm{min}\right)$ & $2001 \pm 424$ & $2130 \pm 327$ & 0.22 \\
\hline \multicolumn{4}{|l|}{ Blood lipids } \\
\hline Total cholesterol $(\mathrm{mmol} / \mathrm{l})$ & $4.7 \pm 0.8$ & $4.7 \pm 0.9$ & 0.81 \\
\hline LDL-cholesterol (mmol/l) & $2.7 \pm 0.7$ & $2.9 \pm 0.7$ & 0.34 \\
\hline HDL-cholesterol (mmol/l) & $1.5 \pm 0.2$ & $1.3 \pm 0.4$ & 0.46 \\
\hline Triglycerides $(\mathrm{mmol} / \mathrm{l})$ & $1.53 \pm 0.68$ & $0.96 \pm 0.34$ & $<0.05$ \\
\hline \multicolumn{4}{|l|}{ Glucose tolerance } \\
\hline Fasting glucose $(\mathrm{mmol} / \mathrm{l})$ & $6.13 \pm 1.33$ & $5.49 \pm 0.42$ & 0.57 \\
\hline Fasting insulin $(\mathrm{pmol} / \mathrm{l})$ & $93.4 \pm 75.7$ & $58.6 \pm 40.0$ & 0.17 \\
\hline Glucose AUC $(\mathrm{mmol} / \mathrm{l}) \times(\mathrm{min})$ & $944 \pm 385$ & $962 \pm 184$ & 0.22 \\
\hline Insulin AUC $(\mathrm{pmol} / \mathrm{l}) \times(\mathrm{min})$ & $65933 \pm 52808$ & $504444 \pm 28513$ & 0.53 \\
\hline \multicolumn{4}{|l|}{ Body composition } \\
\hline Weight (kg) & $80.0 \pm 12.9$ & $79.8 \pm 13.1$ & 1.00 \\
\hline BMI $\left(\mathrm{kg} / \mathrm{m}^{2}\right)$ & $25.7 \pm 3.4$ & $25.3 \pm 3.2$ & 0.84 \\
\hline Lean body mass $(\mathrm{kg})$ & $52.3 \pm 6.6$ & $56.3 \pm 6.6$ & 0.33 \\
\hline Fat mass $(\mathrm{kg})$ & $24.4 \pm 7.5$ & $20.5 \pm 7.7$ & 0.46 \\
\hline Fat percentage (\%) & $31.1 \pm 5.6$ & $25.7 \pm 7.0$ & 0.17 \\
\hline Trunk fat mass $(\mathrm{kg})$ & $14.5 \pm 4.5$ & $12.4 \pm 5.4$ & 0.39 \\
\hline \multicolumn{4}{|l|}{ Inflammatory parameters } \\
\hline $\mathrm{TNF} \alpha(p g / l)$ & $2.58 \pm 1.49$ & $1.61 \pm 0.54$ & $<0.05$ \\
\hline IL6 (pg/l) & $4.94 \pm 3.60$ & $2.71 \pm 1.20$ & $<0.05$ \\
\hline PAl-1 (ng/l) & $3.17 \pm 1.17$ & $3.12 \pm 1.88$ & 0.81 \\
\hline Leptin $(\mathrm{pg} / \mathrm{l})$ & $6584 \pm 6028$ & $3330 \pm 1922$ & 0.19 \\
\hline Adiponectin (ng/l) & $15623 \pm 5842$ & $12793 \pm 3736$ & 0.29 \\
\hline
\end{tabular}

${ }^{\mathrm{a}}$ Data are presented as means \pm S.D. or median (range).

http://erc.endocrinology-journals.org DOI: 10.1530/ERC-12-0393
(C) 2013 Society for Endocrinology Printed in Great Britain 
significantly lower than the testosterone levels of the controls $(13.1 \pm 2.4 \mathrm{nmol} / \mathrm{l})$, who were all considered eugonadal. The median PSA concentration in the patient group was $0.90 \mu \mathrm{g} / \mathrm{l}$ (range: $0.10-6.7 \mu \mathrm{g} / \mathrm{l}$ ) and the median duration of ADT was 9 months (range: 4-71 months). Eight patients were treated with long-term ADT (ADT $\geq 6$ months) and one patient was treated with short-term ADT (ADT $<6$ months).

At baseline, no differences existed between the two groups in age, $\mathrm{VO}_{2 \max }$, and BMI. The patients had an average of $4 \mathrm{~kg} \mathrm{LBM}$ less and $4 \mathrm{~kg}$ of FM more than those of the controls; however, none of the body composition measurements were significantly different at baseline. Plasma concentrations of TNF $\alpha$, IL6, and triglycerides were significantly higher in the patient group, whereas plasma concentrations of PAI-1, leptin, adiponectin, and cholesterol were comparable between the two groups. The measures of glucose tolerance were not different between the groups.

\section{Training}

The median compliance to the training regimen was 100\% (range: 91.7-100\%). During the first 6 weeks, the mean training intensity was $71.1 \pm 6.8 \%$ of $\mathrm{VO}_{2 \max }$, and during the last 6 weeks, it was $74.9 \pm 6.4 \%$ of $\mathrm{VO}_{2 \max }$. Accordingly, the subjects trained at a higher mean intensity than anticipated.

\section{Fitness}

The 12 weeks of endurance training improved $\mathrm{VO}_{2 \max }$ $\left(\mathrm{ml}\left(\mathrm{O}_{2}\right) /\right.$ min per $\left.\mathrm{kg}\right)$ markedly by $11.3 \pm 11.1$ and $12.7 \pm$ $8.4 \%$ in the patients and controls respectively $(P<0.0001)$. When body weight was not taken into consideration, $\mathrm{VO}_{2 \max }\left(\mathrm{ml}\left(\mathrm{O}_{2}\right) / \mathrm{min}\right)$ still increased significantly with $9.8 \pm 11.3 \%$ in the patient group and with $12.0 \pm 9.3 \%$ in the control group $(P<0.001)$. No significant group $\times$ time interactions were observed for $\mathrm{VO}_{2 \max }\left(\mathrm{ml}\left(\mathrm{O}_{2}\right) / \mathrm{min}\right.$ per $\mathrm{kg}$, $\left.P=0.91 ; \mathrm{ml}\left(\mathrm{O}_{2}\right) / \mathrm{min}, P=0.99\right)$ (Table 2 ), and the effect of

Table 2 Effect of endurance training on fitness, metabolic parameters, body composition, and inflammatory parameters in the blood in the patients and controls

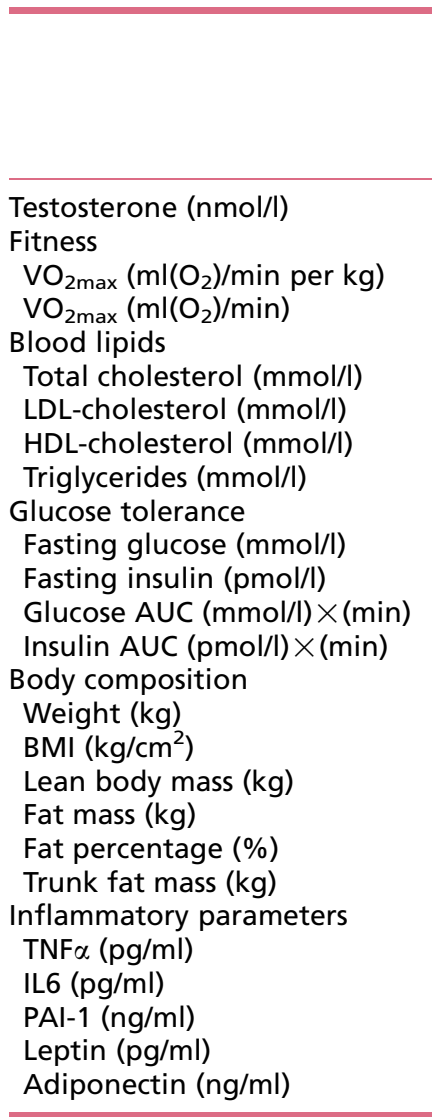

\begin{tabular}{|c|c|}
\hline \multicolumn{2}{|c|}{ Patients $(n=9)$} \\
\hline Pre & Post \\
\hline $0.49 \pm 0.37$ & $0.37 \pm 0.26$ \\
\hline $\begin{array}{c}25.2 \pm 4.2 \\
2001 \pm 424\end{array}$ & $\begin{array}{c}29.0 \pm 3.8 \\
2295 \pm 585\end{array}$ \\
\hline $4.7 \pm 0.8$ & $4.7 \pm 0.7$ \\
\hline $2.7 \pm 0.7$ & $2.6 \pm 0.5$ \\
\hline $1.5 \pm 0.2$ & $1.5 \pm 0.3$ \\
\hline $1.53 \pm 0.68$ & $1.14 \pm 0.27$ \\
\hline $6.13 \pm 1.33$ & $5.77 \pm 0.66$ \\
\hline $93.4 \pm 75.7$ & $78.3 \pm 72.6$ \\
\hline $944 \pm 385$ & $931 \pm 313$ \\
\hline $65933 \pm 52808$ & $66757 \pm 63233$ \\
\hline $80.0 \pm 12.9$ & $78.5 \pm 13.2$ \\
\hline $25.7 \pm 3.4$ & $25.2 \pm 3.5$ \\
\hline $52.3 \pm 6.6$ & $52.3 \pm 6.3$ \\
\hline $24.4 \pm 7.5$ & $23.1 \pm 7.7$ \\
\hline $31.1 \pm 5.6$ & $29.8 \pm 6.4$ \\
\hline $14.5 \pm 4.7$ & $13.4 \pm 4.5$ \\
\hline $2.58 \pm 1.49$ & $2.38 \pm 1.45$ \\
\hline $4.94 \pm 3.60$ & $3.39 \pm 1.60$ \\
\hline $3.17 \pm 1.17$ & $2.40 \pm 1.69$ \\
\hline $6584 \pm 6028$ & $4645 \pm 3616$ \\
\hline $15623 \pm 5842$ & $15807 \pm 4287$ \\
\hline
\end{tabular}

\begin{tabular}{c}
\hline Controls \\
Pre \\
\hline $13.13 \pm 2.4$ \\
$27.1 \pm 3.3$ \\
$2130 \pm 327$ \\
$4.7 \pm 1.0$ \\
$2.9 \pm 0.7$ \\
$1.3 \pm 0.4$ \\
$0.96 \pm 0.34$ \\
\\
$5.49 \pm 0.42$ \\
$58.6 \pm 40.0$ \\
$962 \pm 184$ \\
$50444 \pm 28513$ \\
$79.8 \pm 13.1$ \\
$25.3 \pm 3.2$ \\
$56.3 \pm 6.6$ \\
$20.5 \pm 7.7$ \\
$25.7 \pm 7.0$ \\
$12.4 \pm 5.4$ \\
$1.61 \pm 0.54$ \\
$2.71 \pm 1.20$ \\
$3.12 \pm 1.88$ \\
$3330 \pm 1922$ \\
$12793 \pm 3736$ \\
\end{tabular}

\begin{tabular}{c}
\hline $\begin{array}{c}\text { Interaction } \\
\text { group } \times \text { time }\end{array}$ \\
\hline$P$ value \\
\hline 0.24 \\
\\
0.91 \\
0.99 \\
\\
0.87 \\
0.89 \\
0.66 \\
0.09 \\
\\
0.72 \\
0.59 \\
0.24 \\
0.83 \\
\\
0.32 \\
0.35 \\
0.87 \\
0.57 \\
0.46 \\
0.37 \\
\\
0.06 \\
0.06 \\
0.46 \\
0.43 \\
0.71 \\
\end{tabular}

\begin{tabular}{c}
$\begin{array}{c}\text { Effect } \\
\text { of time }\end{array}$ \\
\hline$P$ value \\
\hline 0.40 \\
\\
$<\mathbf{0 . 0 0 0 1}$ \\
$<\mathbf{0 . 0 0 1}$ \\
\\
0.61 \\
0.34 \\
$<0.05$ \\
0.12 \\
\\
$<0.05$ \\
0.30 \\
0.21 \\
0.49 \\
\\
$<0.0001$ \\
$<0.0001$ \\
0.99 \\
$<0.01$ \\
$<0.05$ \\
$<0.01$ \\
0.83 \\
0.68 \\
0.18 \\
0.08 \\
0.46 \\
\end{tabular}

Data are presented as means \pm s.D. $P$ values for the effect of time reflect an effect of training in the two groups pooled together. 
the training regimen on $\mathrm{VO}_{2 \max }$ was, therefore, not different between the two groups.

\section{Metabolic parameters}

A significant effect of time for increased HDL-cholesterol concentrations $(P<0.05)$ and for decreased fasting glucose concentrations $(P<0.05)$ was achieved in response to the training regimen. No significant group $\times$ time interactions were observed for the metabolic parameters (Table 2).

\section{Insulin sensitivity}

Plasma glucose concentration was maintained at $\sim 5.5 \mathrm{mmol} / \mathrm{l}$ during the clamp pre $(5.41 \pm 0.16 \mathrm{mmol} / 1$ in the patients and $5.37 \pm 0.16 \mathrm{mmol} / \mathrm{l}$ in the controls) and post $(5.35 \pm 0.24 \mathrm{mmol} / \mathrm{l}$ in the patients and $5.38 \pm$ $0.13 \mathrm{mmol} / \mathrm{l}$ in the controls) training. Basal and insulinstimulated glucose $R_{d}$ and $R_{a}$ were similar between the two groups before the start of the training regimen. The training regimen led to no changes in basal glucose $R_{d}$ $(P=0.17)$ and $\mathrm{R}_{\mathrm{a}}(P=0.17)$. Insulin-stimulated $\mathrm{R}_{\mathrm{a}}$ was also unaffected by the training regimen $(P=0.32)$, even though eight of nine subjects in the patient group and seven of nine subjects in the control group exhibited a decreased insulin-stimulated $\mathrm{R}_{\mathrm{a}}$ in response to the training. A significant effect of training was observed in insulinstimulated $\mathrm{R}_{\mathrm{d}}(P<0.05)$, which increased by $14.3 \pm 19.8 \%$ in the patient group and by $11.4 \pm 20.8 \%$ in the control group. No significant group $\times$ time interactions were observed for either basal or insulin-stimulated $R_{a}$ ( $P=0.76$ and $P=0.40$ respectively) and $\mathrm{R}_{\mathrm{d}}(P=0.76$ and $P=0.77$ respectively) (Fig. $1 \mathrm{~A}$ and $\mathrm{B}$ ).

\section{Western blotting}

The endurance training performed in the present study increased muscle protein content of both GLUT4 and AKT $(P<0.05$ and $P<0.01$ respectively); however, no significant group $\times$ time effects were observed $(P=0.62$ and $P=0.13$ respectively) (Fig. 2A and B).

\section{Body composition}

LBM remained unchanged in response to the training $(P=0.99)$, whereas a marked reduction was observed for weight $(P<0.0001)$, BMI $(P<0.0001)$, FM $(P<0.01)$, and trunk FM $(P<0.01)$. No significant group $\times$ time interactions were observed for weight $(P=32)$, BMI $(P=0.35)$, LBM $(P=0.87)$, FM $(P=0.57)$, and trunk FM
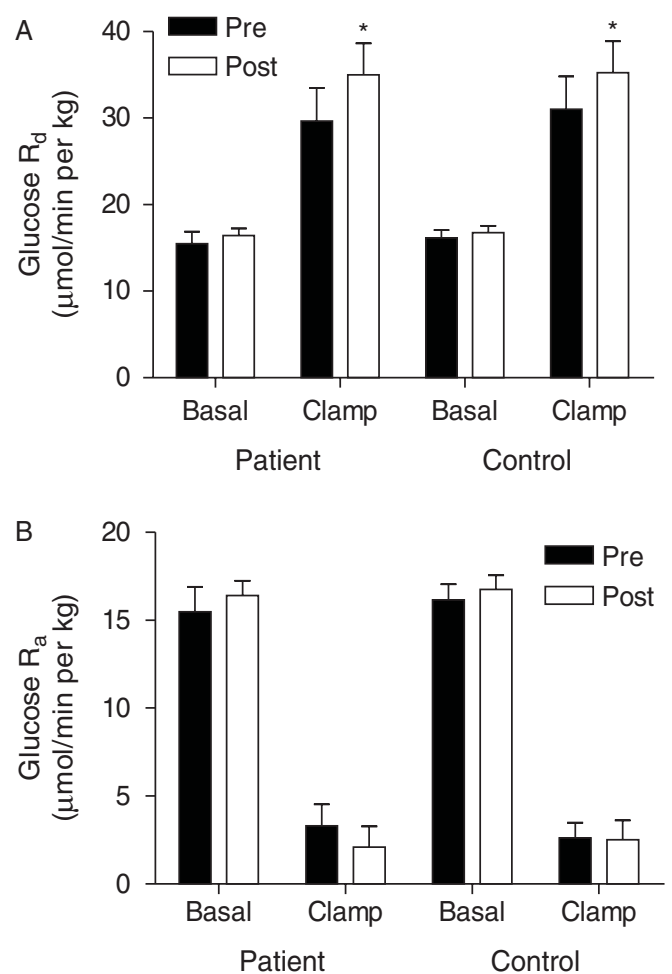

Figure 1

Mean glucose $R_{d}(A)$ and $R_{a}(B)$ expressed as $\mu \mathrm{mol} / \mathrm{min}$ per $\mathrm{kg}$ during the basal state and during the last 30 min of the clamp pre and post 12 weeks of endurance training. Due to technical problems during the post-intervention clamp in one control subject, data are presented for $n=9$ in the control group. Data are expressed as means \pm s.D. $* P<0.05$ for an effect of training in the two groups pooled together.

$(P=0.37)$ (Table 2). The effect of the training regimen in the two groups on these parameters was thus equal.

The reduction in the amount of abdominal fat was $(P<0.01) \quad 6.3 \pm 4.7$ and $3.9 \pm 8.3 \%$ in the patient and control groups respectively in response to the training. The reduction in the amount of abdominal fat was reflected by a decrease of $8.4 \pm 7.8$ and $5.8 \pm 12.0 \%$ in that of VAT $(P<0.01)$ and of $4.9 \pm 3.5$ and $2.5 \pm 8.1 \%$ in that of SAT $(P<0.05)$ in the patients and controls respectively (Fig. 3A, B, and C). These changes in body composition in response to the training were, however, not different between the two groups, since no significant interactions for group $\times$ time were observed for abdominal FM $(P=0.45)$, VAT $(P=0.56)$, or SAT $(P=0.41)$. In contrast, a significant group $\times$ time interaction was observed for IMAT $(P=0.01)$. Post hoc analysis revealed a significant reduction of $8.5 \pm 6.8 \%$ in IMAT amount in the control group $(P<0.05)$, which was not observed in the patient group $(P=0.64)$ (Fig. 3D).

Published by Bioscientifica Ltd 

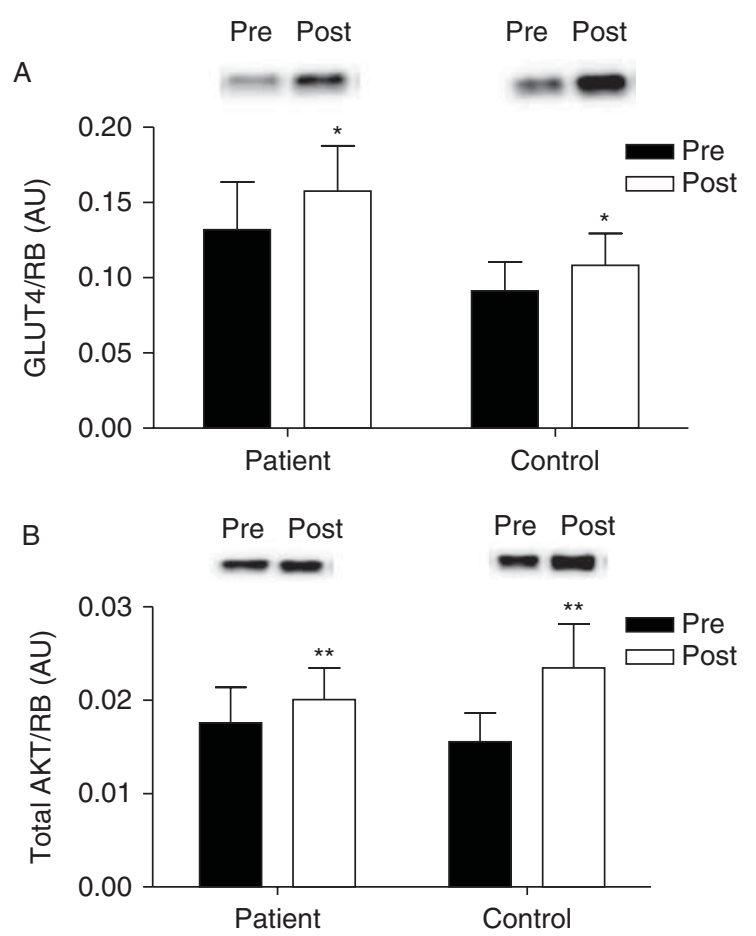

\section{Figure 2}

Muscle protein content of GLUT4 (A) and total AKT (B) normalized to the intensity of the Reactive Brown (RB) total protein stain pre and post 12 weeks of endurance training. One patient refused to have biopsies taken and one sample from a control was degraded; therefore, $n=8$ in the patient group and $n=9$ in the control group. Results are reported in arbitrary units (AU). Representative blots for GLUT4 and total AKT protein expression are shown. Data are expressed as means \pm s.D. ${ }^{*} P<0.05$ and $* * P<0.01$ for an effect of training in the two groups pooled together.

\section{Inflammatory markers}

The inflammatory profile did not change in response to the training, and no group $\times$ time interactions were observed for any of the measured systemic inflammatory markers, even though a tendency for an effect existed for TNF $\alpha$ and IL6 (both $P=0.06$ ) (Table 2).

\section{Discussion}

The present study was performed to elucidate whether endurance training improves insulin sensitivity and body composition in ADT-treated prostate cancer patients. Twelve weeks of endurance training improved $\mathrm{VO}_{2 \max }$, peripheral tissue insulin sensitivity, and body composition, including a reduction in the amount of VAT. These changes were of the same magnitude as those observed in healthy control subjects. The control group achieved a reduction in the amount of thigh IMAT, which was not observed in the patient group. The present study demonstrates that endurance training can be used as an approach to improve the overall health in prostate cancer patients receiving ADT and that normal testosterone production is not a requirement to achieve the beneficial effects of endurance training.

Recently, physical training has gained huge interest as a means to counteract the adverse side effects of the ADT given to prostate cancer patients (Segal et al. 2003, Galvao et al. 2006, 2008, 2010, 2011, Hansen et al. 2009, Alberga et al. 2012). The present study is the second to employ endurance training as a mode of exercise (Alberga et al. 2012), but the first to show that men with castration levels of testosterone are capable of enhancing their aerobic capacity at a magnitude comparable to that of agematched eugonadal men. The present study, thereby, demonstrates that the castration levels of testosterone in men do not preclude an increase in aerobic capacity in response to endurance training.

Even though insulin resistance is a well-known and serious side effect of ADT in prostate cancer patients (Basaria et al. 2006, Smith et al. 2006, 2008a, Hamilton et al. 2011), no other studies have investigated the effect of a training intervention on insulin sensitivity in this group of patients. No significant effect of training was observed on insulin-stimulated glucose $\mathrm{R}_{\mathrm{a}}$. However, eight of nine subjects in the patient group actually exhibited a decreased glucose $\mathrm{R}_{\mathrm{a}}$ during insulin stimulation, indicating that hepatic adaptations in insulin sensitivity might occur in response to endurance training. In line with previous studies carried out in non-cancer patients (Shojaee-Moradie et al. 2007, Lindegaard et al. 2008), insulin sensitivity in the peripheral tissue increased in response to the training regimen. The present study thereby highlights that testosterone ablation in men does not obstruct the ability of the peripheral tissue to increase sensitivity to insulin in response to training stimuli. The molecular mechanisms underlying this adaptation of the peripheral tissue seem to involve changes in the insulin signaling cascade. As such, muscle expression of both GLUT4 and total AKT was upregulated in response to the training regimen.

Both the patients and controls lost body weight in response to the training. In both the groups, the decline in body weight was exclusively reflected by a reduced amount of adipose tissue and was not prompted by a reduction in the amount of LBM. LBM is a crucial contributor to muscle strength, functional performance, and ultimately avoidance of accidental falls, all of which are negatively affected by ADT (Bylow et al. 2008, Galvao et al. 2009). Prostate cancer patients exhibit a continuous decrease in the amount of LBM at least 2 years after ADT

Published by Bioscientifica Ltd 
A
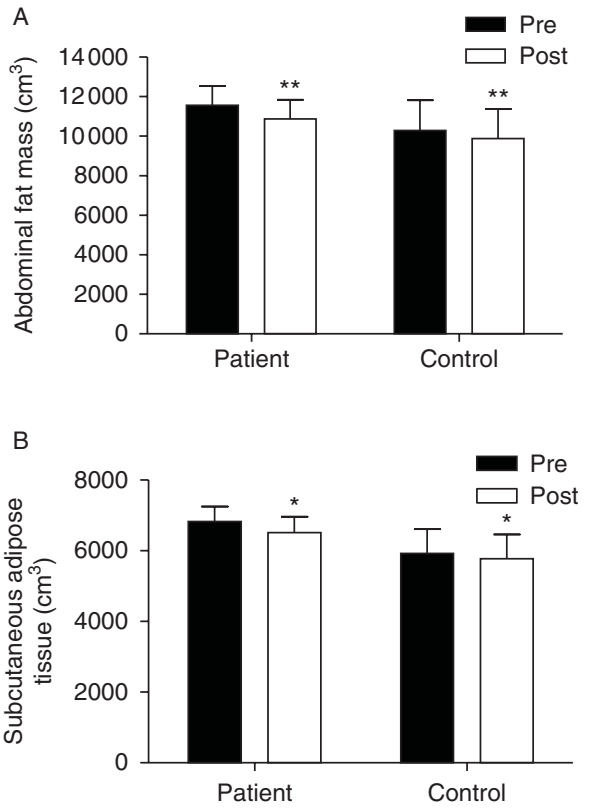

Figure 3

Abdominal fat mass (A), subcutaneous adipose tissue (B), visceral adipose tissue (C), and intermuscular adipose tissue (D) expressed as $\mathrm{cm}^{3}$ pre and post 12 weeks of endurance training. Due to metal implants in the foot one subject in the patient group did not have MR scans performed;

initiation (van Londen et al. 2008). The unchanged amount of LBM in the patient group might, therefore, be of clinical importance and emphasizes that endurance training does not seem to accelerate the loss of muscle in prostate cancer patients receiving ADT.

The present study underlines that ADT-treated prostate cancer patients are capable of reducing the amount of body fat in response to endurance training. However, one patient, who was receiving short-term ADT ( $<6$ months), did not respond to the training regimen with regard to body composition and gained $2.6 \mathrm{~kg}$ of FM and lost as much as $5.0 \mathrm{~kg}$ of LBM (data not shown). The adverse changes in body composition primarily take place during the initial year of treatment (Greenspan et al. 2005, Lee et al. 2005, van Londen et al. 2008, Kim et al. 2011), with more than $80 \%$ of the changes occurring during the first 6 months (Smith et al. 2008b). We, therefore, speculate that the duration of prior ADT exposure might affect the training outcome in body composition, signifying no mitigating effect of a training intervention on the pronounced alterations in body composition during the early phase of ADT. Although speculative, this suggestion is supported by a recent study carried out by Galvao et al. (2011), showing increased LBM and decreased FM in long-term ADT users ( $>6$ months) and increased FM and no change in LBM in short-term ADT
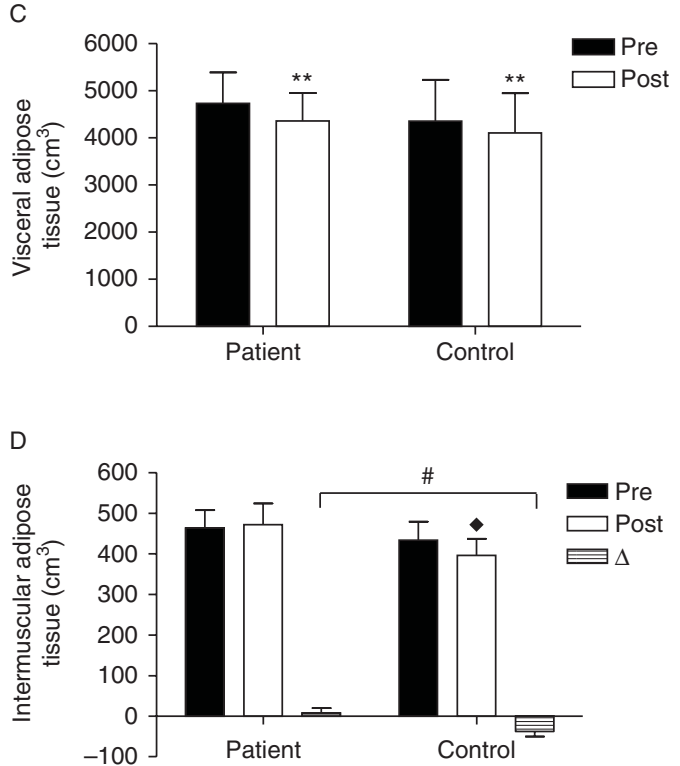

therefore, $n=8$ in the patient group. Data are expressed as means \pm s.D. $\star P<0.05$ and $* * P<0.01$, for an effect of training in the two groups pooled together. $\bullet<0.05$ for an effect of training in the control group and ${ }^{\#} P<0.05$ between the $\Delta$ values of the two groups.

users ( $<6$ months) in response to 12 weeks of combined strength and aerobic training.

The effect of ADT on IMAT is currently unknown. However, elevated testosterone concentration is associated with less IMAT infiltration in older men (Miljkovic et al. 2011) and testosterone administration dose dependently decreases the amount of IMAT in young men (Woodhouse et al. 2004). Thus, a rationale exists for an increased deposition of IMAT in prostate cancer patients receiving ADT. The proximity and vascular connection of IMAT to the muscle tissue probably have detrimental effects on glucose metabolism (Goodpaster et al. 2000, 2003, Yim et al. 2007, Durheim et al. 2008, Boettcher et al. 2009). The reduction in fasting glucose concentration might, therefore, in part have been mediated by the decreased deposition of IMAT in response to the training in the control group. Previous studies have shown that IMAT is modified by the level of physical activity (Manini et al. 2007, Durheim et al. 2008, Goodpaster et al. 2008, Murphy et al. 2012). The absent effect of the training intervention on IMAT in the patient group is, therefore, surprising and needs further attention in future studies.

In contrast to IMAT deposition, equal reductions were noted in abdominal fat, VAT, and SAT amounts in

Published by Bioscientifica Ltd. 
response to the training. In particular, the reduction in the amount of VAT is of great importance, since the accumulation of adipose tissue in this compartment is more strongly associated with insulin resistance and type 2 diabetes compared with SAT (Bray et al. 2008, Preis et al. 2010). The reasons for this are multiple. VAT is characterized by being more inflamed than SAT with an increased secretion of, for instance, IL6 and PAI-1 (Cancello \& Clement 2006). VAT is also more lipolytically active and releases more free fatty acids (FFAs) into the circulation compared with SAT (Wajchenberg et al. 2002). As a consequence, viscerally obese people have a higher systemic concentration of FFAs (Nielsen et al. 2004), which increases the risk of ectopic fat deposition in the insulinsensitive tissue of the muscle, liver, and pancreas (Nielsen et al. 2004, Rossi et al. 2011). Furthermore, the portal vein drains VAT directly into the liver, where an increased supply of FFAs decreases the inhibition of insulinstimulated glucose production and reduces the removal of insulin (Wajchenberg et al. 2002, Nielsen et al. 2004). Thus, the reduction in the amount of VAT is an important finding of the present study, and it may have had an effect on both peripheral tissue and hepatic insulin sensitivity, as observed in eight of nine subjects.

Systemic low-grade inflammation has previously been described in prostate cancer patients in general (Michalaki et al. 2004) and in some, but not all, ADT-treated prostate cancer patients (Drachenberg et al. 1999, Wise et al. 2000, Maggio et al. 2006, Smith et al. 2008a,b, Saylor et al. 2012). In the present study, we found an increased systemic concentration of TNF $\alpha$ and IL6 in the patient group compared with the control group at baseline. The lack of a non-ADT prostate cancer group makes it impossible to conclude whether it is the ADT or prostate cancer in itself that is responsible for the higher concentrations of inflammatory cytokines in the patient group. Endurance training did not alter the systemic concentrations of any of the measured inflammatory markers. These results imply that changes in inflammation status were not the major driving force underlying the improved peripheral tissue insulin sensitivity in the patient group.

Because the testing protocol was rather extensive, the number of subjects included in the study was small. This small number of subjects might, however, have concealed some beneficial effects of the training regimen or baseline differences between the patient and control groups due to a low statistical power. Also, we did not include a non-training control group of prostate cancer patients receiving ADT. This is a limitation of the study, since we are unable to conclude whether endurance training is a true countermeasure of the ADT-induced deterioration in insulin sensitivity and body composition. However, it is important to note that the beneficial effects of exercise in the patient group were equal to those found in the healthy control group. As such, our data are clinically relevant and provide evidence for a therapeutic effect of exercise on metabolism in ADT-treated prostate cancer patients.

In conclusion, the present study demonstrates that endurance training improves insulin sensitivity in the peripheral tissue, although hepatic adaptations cannot be precluded. Endurance training also improves body composition by reducing FM and the amount of VAT in prostate cancer patients receiving ADT, implying that endurance training may lessen the detrimental side effects of ADT. A reduction in treatment side effects seems pivotal to reduce the risk of type 2 diabetes and its concomitant complications in ADT-treated prostate cancer patients. The results of the present study, furthermore, suggest that testosterone is not a prerequisite to achieve an improvement in insulin sensitivity and a reduction in the amount of abdomen-located adipose tissue in response to endurance training. In contrast, testosterone levels may be of importance for an improved deposition of IMAT in response to endurance training.

\section{Declaration of interest}

The authors declare that there is no conflict of interest that could be perceived as prejudicing the impartiality of the research reported.

\section{Funding}

The Centre of Inflammation and Metabolism (CIM) is supported by a grant from the Danish National Research Foundation (no. 02-512-55). This study was further supported by the Danish Medical Research Council, the Commission of the European Communities (Grant Agreement no. 223576 - MYOAGE), and by grants from TrygFonden. CIM is part of the UNIK Project: Food, Fitness and Pharma for Health and Disease, supported by the Danish Ministry of Science, Technology, and Innovation. The Copenhagen Muscle Research Centre (CMRC) is supported by a grant from the Capital Region of Denmark.

\section{Author contribution statement}

T Hvid, C Thomsen, P Iversen, K Brasso, K J Mikines, G van Hall, $\mathrm{B}$ Lindegaard, and $\mathrm{B} K$ Pedersen were responsible for the conception and design of the research. T Hvid, $K$ Winding, A Rinnov, T Dejgaard, $T$ P J Solomon, and B Lindegaard performed the experiments. T Hvid, $K$ Winding, and T P J Solomon analyzed the data. T Hvid, K Winding, $T P$ J Solomon, and B Lindegaard interpreted the results of the experiments. $T$ Hvid prepared the figures. $T$ Hvid drafted the manuscript. T Hvid, K Winding, A Rinnov, T Dejgaard, P Iversen, K Brasso, K J Mikines, $B$ Lindegaard, and B K Pedersen edited and revised the manuscript. T Hvid, K Winding, A Rinnov, T Dejgaard, C Thomsen, P Iversen, K Brasso, K J Mikines, G van Hall, B Lindegaard, and B K Pedersen approved the final version of the manuscript.

Published by Bioscientifica Ltd. 


\section{Acknowledgements}

Thomas S Grøndahl, Jonathan Mathiesen, and Lisa Gruschy are acknowledged for their help with various aspects of the present study. Ruth Rousing, Hanne Villumsen, Noemi James, Ditte L Clement, and Maria Scheel are acknowledged for their technical assistance.

\section{References}

Alberga AS, Segal RJ, Reid RD, Scott CG, Sigal RJ, Khandwala F, Jaffey J, Wells GA \& Kenny GP 2012 Age and androgen-deprivation therapy on exercise outcomes in men with prostate cancer. Supportive Care in Cancer 20 971-981. (doi:10.1007/s00520-011-1169-x)

Basaria S, Muller DC, Carducci MA, Egan J \& Dobs AS 2006 Hyperglycemia and insulin resistance in men with prostate carcinoma who receive androgen-deprivation therapy. Cancer 106 581-588. (doi:10.1002/cncr. 21642)

Berruti A, Dogliotti L, Terrone C, Cerutti S, Isaia G, Tarabuzzi R, Reimondo G, Mari M, Ardissone P, De Luca S et al. 2002 Changes in bone mineral density, lean body mass and fat content as measured by dual energy $\mathrm{X}$-ray absorptiometry in patients with prostate cancer without apparent bone metastases given androgen deprivation therapy. Journal of Urology 167 2361-2367. (doi:10.1016/S0022-5347(05)64985-3)

Boettcher M, Machann J, Stefan N, Thamer C, Haring HU, Claussen CD, Fritsche A \& Schick F 2009 Intermuscular adipose tissue (IMAT): association with other adipose tissue compartments and insulin sensitivity. Journal of Magnetic Resonance Imaging 29 1340-1345. (doi:10.1002/jmri.21754)

Bourke L, Doll H, Crank H, Daley A, Rosario D \& Saxton JM 2011 Lifestyle intervention in men with advanced prostate cancer receiving androgen suppression therapy: a feasibility study. Cancer Epidemiology, Biomarkers \& Prevention 20 647-657. (doi:10.1158/1055-9965.EPI-10-1143)

Boxer RS, Kenny AM, Dowsett R \& Taxel P 2005 The effect of 6 months of androgen deprivation therapy on muscle and fat mass in older men with localized prostate cancer. Aging Male 8 207-212. (doi:10.1080/ 13685530500361226)

Braga-Basaria M, Dobs AS, Muller DC, Carducci MA, John M, Egan J \& Basaria S 2006 Metabolic syndrome in men with prostate cancer undergoing long-term androgen-deprivation therapy. Journal of Clinical Oncology 24 3979-3983. (doi:10.1200/JCO.2006.05.9741)

Bray GA, Jablonski KA, Fujimoto WY, Barrett-Connor E, Haffner S, Hanson RL, Hill JO, Hubbard V, Kriska A, Stamm E et al. 2008 Relation of central adiposity and body mass index to the development of diabetes in the Diabetes Prevention Program. American Journal of Clinical Nutrition 87 1212-1218.

Bylow K, Dale W, Mustian K, Stadler WM, Rodin M, Hall W, Lachs M \& Mohile SG 2008 Falls and physical performance deficits in older patients with prostate cancer undergoing androgen deprivation therapy. Urology 72 422-427. (doi:10.1016/j.urology.2008.03.032)

Cancello R \& Clement K 2006 Is obesity an inflammatory illness? Role of low-grade inflammation and macrophage infiltration in human white adipose tissue BJOG : an International Journal of Obstetrics and Gynaecology 113 1141-1147. (doi:10.1111/j.1471-0528.2006.01004.x)

Drachenberg DE, Elgamal AA, Rowbotham R, Peterson M \& Murphy GP 1999 Circulating levels of interleukin-6 in patients with hormone refractory prostate cancer. Prostate 41 127-133. (doi:10.1002/ (SICI)1097-0045(19991001)41:2 < 127::AID-PROS7> 3.0.CO;2-H)

Durheim MT, Slentz CA, Bateman LA, Mabe SK \& Kraus WE 2008 Relationships between exercise-induced reductions in thigh intermuscular adipose tissue, changes in lipoprotein particle size, and visceral adiposity. American Journal of Physiology. Endocrinology and Metabolism 295 E407-E412. (doi:10.1152/ajpendo.90397.2008)

Faris JE \& Smith MR 2010 Metabolic sequelae associated with androgen deprivation therapy for prostate cancer. Current Opinion in
Endocrinology, Diabetes, and Obesity 17 240-246. (doi:10.1097/MED Ob013e3283391fd1)

Fox CS, Massaro JM, Hoffmann U, Pou KM, Maurovich-Horvat P, Liu CY, Vasan RS, Murabito JM, Meigs JB, Cupples LA et al. 2007 Abdominal visceral and subcutaneous adipose tissue compartments: association with metabolic risk factors in the Framingham Heart Study. Circulation 116 39-48. (doi:10.1161/CIRCULATIONAHA.106.675355)

Galvao DA, Nosaka K, Taaffe DR, Spry N, Kristjanson LJ, McGuigan MR, Suzuki K, Yamaya K \& Newton RU 2006 Resistance training and reduction of treatment side effects in prostate cancer patients. Medicine and Science in Sports and Exercise 38 2045-2052. (doi:10.1249/01.mss. $0000233803.48691 .8 \mathrm{~b})$

Galvao DA, Nosaka K, Taaffe DR, Peake J, Spry N, Suzuki K, Yamaya K, McGuigan MR, Kristjanson LJ \& Newton RU 2008 Endocrine and immune responses to resistance training in prostate cancer patients. Prostate Cancer and Prostatic Diseases 11 160-165. (doi:10.1038/sj.pcan. 4500991)

Galvao DA, Taaffe DR, Spry N, Joseph D, Turner D \& Newton RU 2009 Reduced muscle strength and functional performance in men with prostate cancer undergoing androgen suppression: a comprehensive cross-sectional investigation. Prostate Cancer and Prostatic Diseases 12 198-203. (doi:10.1038/pcan.2008.51)

Galvao DA, Taaffe DR, Spry N, Joseph D \& Newton RU 2010 Combined resistance and aerobic exercise program reverses muscle loss in men undergoing androgen suppression therapy for prostate cancer without bone metastases: a randomized controlled trial. Journal of Clinical Oncology 28 340-347. (doi:10.1200/JCO.2009.23.2488)

Galvao DA, Taaffe DR, Spry N, Joseph D \& Newton RU 2011 Acute versus chronic exposure to androgen suppression for prostate cancer: impact on the exercise response. Journal of Urology 186 1291-1297. (doi:10.1016/j.juro.2011.05.055)

Goodpaster BH, Thaete FL \& Kelley DE 2000 Thigh adipose tissue distribution is associated with insulin resistance in obesity and in type 2 diabetes mellitus. American Journal of Clinical Nutrition 71 885-892.

Goodpaster BH, Krishnaswami S, Resnick H, Kelley DE, Haggerty C, Harris TB, Schwartz AV, Kritchevsky S \& Newman AB 2003 Association between regional adipose tissue distribution and both type 2 diabetes and impaired glucose tolerance in elderly men and women. Diabetes Care 26 372-379. (doi:10.2337/diacare.26.2.372)

Goodpaster BH, Chomentowski P, Ward BK, Rossi A, Glynn NW, Delmonico MJ, Kritchevsky SB, Pahor M \& Newman AB 2008 Effects of physical activity on strength and skeletal muscle fat infiltration in older adults: a randomized controlled trial. Journal of Applied Physiology $\mathbf{1 0 5}$ 1498-1503. (doi:10.1152/japplphysiol.90425.2008)

Greenspan SL, Coates P, Sereika SM, Nelson JB, Trump DL \& Resnick NM 2005 Bone loss after initiation of androgen deprivation therapy in patients with prostate cancer. Journal of Clinical Endocrinology and Metabolism 90 6410-6417. (doi:10.1210/jc.2005-0183)

Hamilton EJ, Gianatti E, Strauss BJ, Wentworth J, Lim-Joon D, Bolton D, Zajac JD \& Grossmann M 2011 Increase in visceral and subcutaneous abdominal fat in men with prostate cancer treated with androgen deprivation therapy. Clinical Endocrinology 74 377-383. (doi:10.1111/j. 1365-2265.2010.03942.x)

Hansen PA, Dechet CB, Porucznik CA \& LaStayo PC 2009 Comparing eccentric resistance exercise in prostate cancer survivors on and off hormone therapy: a pilot study. PM \& R: The Journal of Injury, Function, and Rehabilitation 1 1019-1024. (doi:10.1016/j.pmrj.2009.09.016)

Hanson ED, Sheaff AK, Sood S, Ma L, Francis JD, Goldberg AP \& Hurley BF 2013 Strength training induces muscle hypertrophy and functional gains in black prostate cancer patients despite androgen deprivation therapy. Journals of Gerontology. Series A, Biological Sciences and Medical Sciences 68 490-498. (doi:10.1093/gerona/gls206)

Hawley JA \& Lessard SJ 2008 Exercise training-induced improvements in insulin action. Acta Physiologica 192 127-135. (doi:10.1111/j.1748 1716.2007.01783.x) 
Keating NL, O'Malley AJ \& Smith MR 2006 Diabetes and cardiovascular disease during androgen deprivation therapy for prostate cancer. Journal of Clinical Oncology 24 4448-4456. (doi:10.1200/JCO.2006.06.2497)

Kim HS, Moreira DM, Smith MR, Presti JC Jr, Aronson WJ, Terris MK, Kane CJ, Amling CL \& Freedland SJ 2011 A natural history of weight change in men with prostate cancer on androgen-deprivation therapy (ADT): results from the Shared Equal Access Regional Cancer Hospital (SEARCH) database. BJU International 107 924-928. (doi:10.1111/ j.1464-410X.2010.09679.x)

Kintzel PE, Chase SL, Schultz LM \& O'Rourke TJ 2008 Increased risk of metabolic syndrome, diabetes mellitus, and cardiovascular disease in men receiving androgen deprivation therapy for prostate cancer. Pharmacotherapy 28 1511-1522. (doi:10.1592/phco.28.12.1511)

Lechleitner M 2008 Obesity and the metabolic syndrome in the elderly a mini-review. Gerontology 54 253-259. (doi:10.1159/000161734)

Lee H, McGovern K, Finkelstein JS \& Smith MR 2005 Changes in bone mineral density and body composition during initial and long-term gonadotropin-releasing hormone agonist treatment for prostate carcinoma. Cancer 104 1633-1637. (doi:10.1002/cncr.21381)

Lindegaard B, Hansen T, Hvid T, van Hall G, Plomgaard P, Ditlevsen S, Gerstoft J \& Pedersen BK 2008 The effect of strength and endurance training on insulin sensitivity and fat distribution in human immunodeficiency virus-infected patients with lipodystrophy. Journal of Clinical Endocrinology and Metabolism 93 3860-3869. (doi:10.1210/jc.2007-2733)

van Londen GJ, Levy ME, Perera S, Nelson JB \& Greenspan SL 2008 Body composition changes during androgen deprivation therapy for prostate cancer: a 2-year prospective study. Critical Review in Oncology and Hematology 68 172-177. (doi:10.1016/j.critrevonc.2008.06.006)

Maggio M, Blackford A, Taub D, Carducci M, Ble A, Metter EJ, Braga-Basaria M, Dobs A \& Basaria S 2006 Circulating inflammatory cytokine expression in men with prostate cancer undergoing androgen deprivation therapy. Journal of Andrology 27 725-728. (doi:10.2164/jandrol.106.000141)

Manini TM, Clark BC, Nalls MA, Goodpaster BH, Ploutz-Snyder LL \& Harris TB 2007 Reduced physical activity increases intermuscular adipose tissue in healthy young adults. American Journal of Clinical Nutrition 85 377-384.

Mathur N \& Pedersen BK 2008 Exercise as a mean to control low-grade systemic inflammation. Mediators of Inflammation 2008109502. (doi:10.1155/2008/109502)

Michalaki V, Syrigos K, Charles P \& Waxman J 2004 Serum levels of IL-6 and TNF- $\alpha$ correlate with clinicopathological features and patient survival in patients with prostate cancer. British Journal of Cancer 90 2312-2316. (doi:10.1038/sj.bjc.6602115)

Miljkovic I, Cauley JA, Dressen AS, Gordon CL, Goodpaster BH, Kuller LH, Bunker CH, Patrick AL, Wheeler VW, Orwoll ES et al. 2011 Bioactive androgens and glucuronidated androgen metabolites are associated with subcutaneous and ectopic skeletal muscle adiposity among older black men. Metabolism 60 1178-1185. (doi:10.1016/j.metabol.2010.12.014)

Murphy JC, McDaniel JL, Mora K, Villareal DT, Fontana L \& Weiss EP 2012 Preferential reductions in intermuscular and visceral adipose tissue with exercise-induced weight loss compared with calorie restriction. Journal of Applied Physiology 112 79-85. (doi:10.1152/japplphysiol.00355.2011)

Nielsen S, Guo Z, Johnson CM, Hensrud DD \& Jensen MD 2004 Splanchnic lipolysis in human obesity. Journal of Clinical Investigation 113 1582-1588.

Plomgaard P, Bouzakri K, Krogh-Madsen R, Mittendorfer B, Zierath JR \& Pedersen BK 2005 Tumor necrosis factor- $\alpha$ induces skeletal muscle insulin resistance in healthy human subjects via inhibition of Akt substrate 160 phosphorylation. Diabetes 54 2939-2945. (doi:10.2337/ diabetes.54.10.2939)
Preis SR, Massaro JM, Robins SJ, Hoffmann U, Vasan RS, Irlbeck T, Meigs JB, Sutherland P, D'Agostino RB Sr, O'Donnell CJ et al. 2010 Abdominal subcutaneous and visceral adipose tissue and insulin resistance in the Framingham heart study. Obesity 18 2191-2198. (doi:10.1038/oby.2010.59)

Rossi AP, Fantin F, Zamboni GA, Mazzali G, Rinaldi CA, Del Giglio M, Di Francesco V, Barillari M, Pozzi Mucelli R \& Zamboni M 2011 Predictors of ectopic fat accumulation in liver and pancreas in obese men and women. Obesity 19 1747-1754. (doi:10.1038/oby.2011.114)

Saylor PJ, Kozak KR, Smith MR, Ancukiewicz MA, Efstathiou JA, Zietman AL, Jain RK \& Duda DG 2012 Changes in biomarkers of inflammation and angiogenesis during androgen deprivation therapy for prostate cancer. Oncologist 17 212-219. (doi:10.1634/theoncologist.2011-0321)

Segal RJ, Reid RD, Courneya KS, Malone SC, Parliament MB, Scott CG, Venner PM, Quinney HA, Jones LW, D'Angelo ME et al. 2003 Resistance exercise in men receiving androgen deprivation therapy for prostate cancer. Journal of Clinical Oncology 21 1653-1659. (doi:10.1200/JCO.2003.09.534)

Sharifi N, Gulley JL \& Dahut WL 2005 Androgen deprivation therapy for prostate cancer. Journal of the American Medical Association 294 238-244. (doi:10.1001/jama.294.2.238)

Shojaee-Moradie F, Baynes KC, Pentecost C, Bell JD, Thomas EL, Jackson NC, Stolinski M, Whyte M, Lovell D, Bowes SB et al. 2007 Exercise training reduces fatty acid availability and improves the insulin sensitivity of glucose metabolism. Diabetologia 50 404-413. (doi:10.1007/s00125-006-0498-7)

Smith MR 2004 Changes in fat and lean body mass during androgendeprivation therapy for prostate cancer. Urology 63 742-745. (doi:10.1016/j.urology.2003.10.063)

Smith MR, Finkelstein JS, McGovern FJ, Zietman AL, Fallon MA, Schoenfeld DA \& Kantoff PW 2002 Changes in body composition during androgen deprivation therapy for prostate cancer. Journal of Clinical Endocrinology and Metabolism 87 599-603. (doi:10.1210/jc.87.2.599)

Smith MR, Lee H \& Nathan DM 2006 Insulin sensitivity during combined androgen blockade for prostate cancer. Journal of Clinical Endocrinology and Metabolism 91 1305-1308. (doi:10.1210/jc.2005-2507)

Smith MR, Lee H, Fallon MA \& Nathan DM 2008a Adipocytokines, obesity, and insulin resistance during combined androgen blockade for prostate cancer. Urology 71 318-322. (doi:10.1016/j.urology.2007.08.035)

Smith MR, Lee H, McGovern F, Fallon MA, Goode M, Zietman AL \& Finkelstein JS 2008b Metabolic changes during gonadotropin-releasing hormone agonist therapy for prostate cancer: differences from the classic metabolic syndrome. Cancer 112 2188-2194. (doi:10.1002/cncr.23440)

Steele R 1959 Influences of glucose loading and of injected insulin on hepatic glucose output. Annals of the New York Academy of Sciences 82 420-430. (doi:10.1111/j.1749-6632.1959.tb44923.x)

Wajchenberg BL, Giannella-Neto D, da Silva ME \& Santos RF 2002 Depotspecific hormonal characteristics of subcutaneous and visceral adipose tissue and their relation to the metabolic syndrome. Hormone and Metabolic Research 34 616-621. (doi:10.1055/s-2002-38256)

Wise GJ, Marella VK, Talluri G \& Shirazian D 2000 Cytokine variations in patients with hormone treated prostate cancer. Journal of Urology 164 722-725. (doi:10.1016/S0022-5347(05)67289-8)

Woodhouse LJ, Gupta N, Bhasin M, Singh AB, Ross R, Phillips J \& Bhasin S 2004 Dose-dependent effects of testosterone on regional adipose tissue distribution in healthy young men. Journal of Clinical Endocrinology and Metabolism 89 718-726. (doi:10.1210/jc.2003-031492)

Yim JE, Heshka S, Albu J, Heymsfield S, Kuznia P, Harris T \& Gallagher D 2007 Intermuscular adipose tissue rivals visceral adipose tissue in independent associations with cardiovascular risk. International Journal of Obesity 31 1400-1405. (doi:10.1038/sj.ijo.0803621)

Received in final form 25 May 2013

Accepted 6 June 2013

Made available online as an Accepted Preprint

6 June 2013 http://erc.endocrinology-journals.org DOI: 10.1530/ERC-12-0393 (c) 2013 Society for Endocrinology Printed in Great Britain 